\title{
LIBRO BLANCO DE OPERACIÓN Y MANTENIMIENTO DE LAS BALSAS DE AGUA BRUTA, ¿CUÁNDO?
}

\author{
Guillen Torres J. (1-2), Campo Buetas F. (2); Campo Paul A. (2); Carmen Garcés D. (2).
}

${ }^{1}$ Dr. Ingeniero Agrónomo, profesor titular de la Universidad de Zaragoza. Expresidente CR Lasesa. Vicepresidente de la Asociación Española de Dirección e Ingeniería de Proyectos. Certificado Nivel B como Director de Proyectos del sistema 4LC de IPMA. E-mail: iguitor@unizar.es

${ }^{2}$ Equipo de ingenieros industriales y agrónomos de Limpiabalsas SL. E-mail: clientes@limpiabalsas.com

\section{SINOPSIS}

Más de una docena de grados y masters habilitan administrativamente en la geografía española para diseñar, proyectar, y dirigir, la construcción de una balsa de agua, perfectamente impermeabilizada y con unas garantías de seguridad, que la experiencia ha demostrado incuestionables: es difícil encontrar reseñas de daños significativos a terceros por reventones.

Algunas de ellas pueden calificarse de balsas de autor, diseñadas obviando que se trata de una inversión intensiva en capital, pero con costes de explotación no despreciables para que pueda prestar servicio durante varias generaciones. Construidas, en alguna medida, con apoyo público, y que han entrado en explotación sin un libro de Operación y Mantenimiento (manual de usuario), que oriente a los técnicos que tengan la responsabilidad de operarlas y mantenerlas.

Además, los parámetros constructivos básicos, medidos durante un lustro en más de 600 balsas en explotación, de tamaño superior a $0.8 \mathrm{H}^{\mathrm{a}}$ de superficie horizontal impermeabilizada, pone en evidencia que no siempre coinciden los planos finales de construcción (cuando los hay distintos a los de proyecto), con lo realmente encontrado.
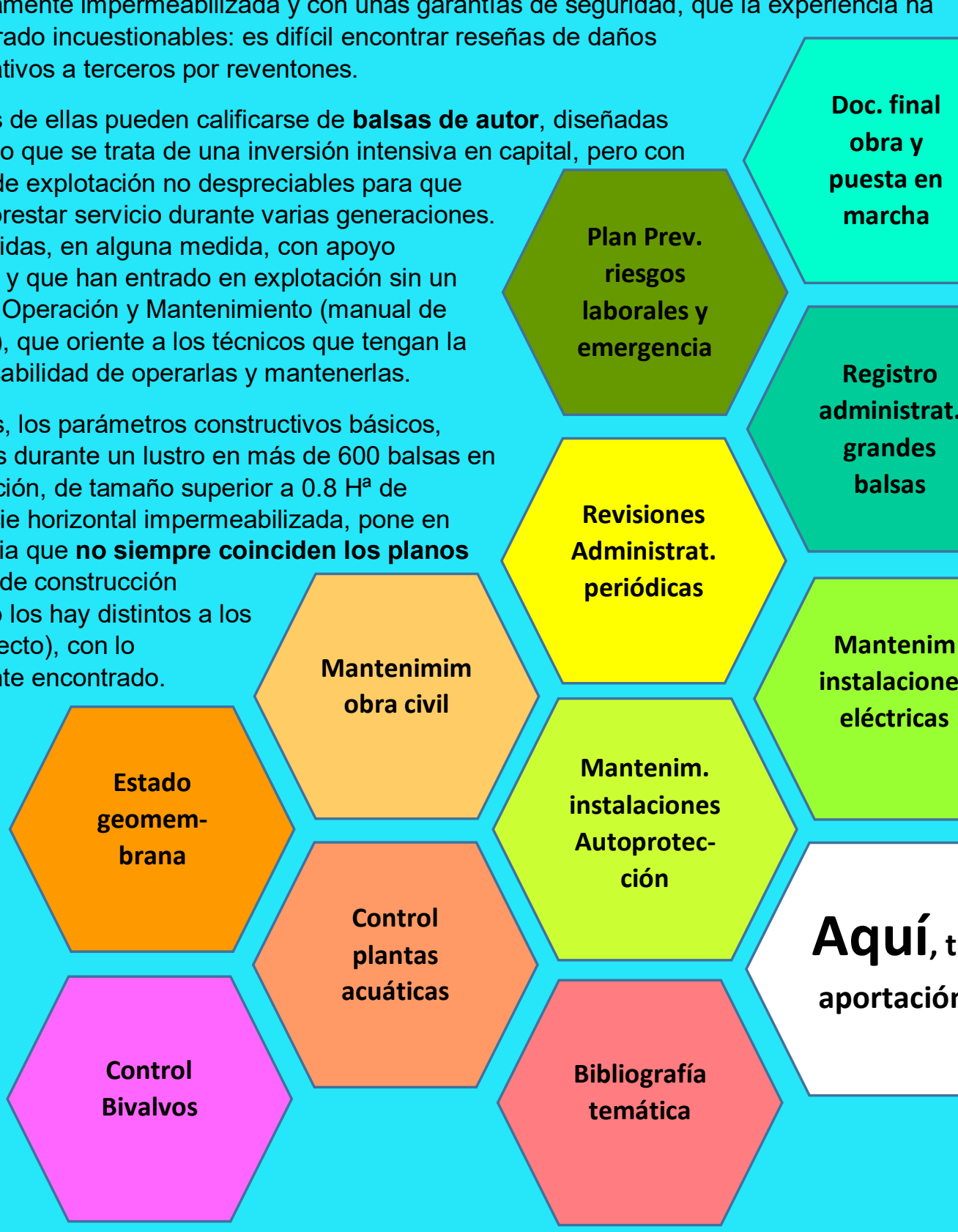